\title{
Conceptual Understanding in Secondary School Chemistry: A Discussion of the Difficulties Experienced by Students
}

\author{
${ }^{1}$ Kamisah Osman and ${ }^{2}$ Nur Suhaidah Sukor \\ ${ }^{1}$ Department of Methodology and Educational Practices, \\ Faculty of Education, The National University of Malaysia, Malaysia \\ ${ }^{2}$ National Secondary School of Sandakan, Sandakan, Sabah, Malaysia
}

Received 2012-05-01, Revised 2012-09-24; Accepted 2013-05-17

\begin{abstract}
It has been widely discussed that students' conceptual alternatives in science play a vital role in shaping their scientific understanding acquired through formal science learning. As one of the components in the science subject, students coming to chemistry lessons also bring in them own chemistry conceptual alternatives. It is widely argued that meaningful learning occurrs if students' actively construct their own understanding out of conceptions they already possess. Thus, it is inescapable that students will need to draw on their alternative conceptions and perhaps rearrange or refuse them to form new concepts. Specifically, this study intends to investigate the conceptual alternatives that students hold in chemistry. The Conceptual Chemistry Test containing 23 multiple choice items which covered 7 topics in the Malaysian Secondary Chemistry Syllabus was specifically designed to reveal students' alternative conception in chemistry. The respondents comprised 317 Form Five students who took chemistry in school. The reliability of the instrument was measured using Kuder-Richardson (KR-20) and the result showed a moderate value of .50. The researchers, with the help of chemistry experts, have developed the test content and face validity. The result showed that students' mean score was below 40 and this indicated that they hold significant alternative conception in chemistry. The implication of this research is to emphasize effort to motivate chemistry teachers to use alternative strategies, such as constructivism and cognitive scaffolding in an effort to remedy students' existing conceptual alternatives.
\end{abstract}

Keywords: Conceptual Alternatives, Conceptual Understanding, Chemistry Teaching, Chemistry Learning

\section{INTRODUCTION}

It was recently reported that $20 \%$ of Malaysian students failed to achieve the minimum standard in science and mathematics as measured in TIMSS (2007) compared to $5 \%$ in science and $7 \%$ in mathematics four years ago (Ruddock et al., 2007). This situation shows that over time, education in the Malaysian classroom has not been successful in improving students' performance. As one of the major hindrances in meaningful scientific understanding, it is argued that low performance in science is caused by students' alternative conceptions.
As pointed by Pfundt and Duit (1991), students' alternative conceptions are highly resistant to change and strongly influence new learning. Students' conceptual alternatives became the focus of study because Chiu (2007) stated that students have an incomplete, underdeveloped and flawed structure of various levels of knowledge about chemistry. Incomplete knowledge in chemistry shows students hold conceptual alternatives and this eventually is associated with a low science score in TIMSS (2007).

Research about students' preconception comes with many different terms; for example misconception,

Corresponding Author: Kamisah Osman, Department of Methodology and Educational Practices, Faculty of Education, The National University of Malaysia, Malaysia 
alternatives conception and pre-scientific conceptions. In this study, the term "alternatives conception" will be used because Chiu (2007) argued that alternatives conception refers to experience-based explanations which are constructed by learners themselves. These are contextually valid, rational and eventually yielded more fruitful conceptions.

Theoretically student conceptions are built from their interaction with other people or learning mediums. Demircioglu et al. (2005) gathered reports from previous research and stated that sources of misconception in chemistry are due to daily life experience; traditional instructional language; teachers; mismatches between teacher and students' knowledge of science; changes in the meaning of chemical terms and textbooks. Schmidt et al. (2007) stated that previous research reported that alternatives conception is caused by students receiving misleading or erroneous concepts and information. In the same report, Sanger and Greenbowe (1999) revealed that textbooks contain misleading statements that would justify students' developing alternatives conception.

This shows that there is an abundance of misconception sources and that they can occur inside and outside the classroom. Griffiths and Preston (1992) concurred with Driver and Easley (1978) that these conceptions are often strongly resistant to traditional teaching and form coherent, though mistaken, conceptual structures within the students' learning experience.

As part of pure science subjects, it is widely acknowledged that chemistry is one of the most difficult subjects in secondary science. Secondary school chemistry contains quantitative and qualitative aspects of chemical reactions that need to be understood in order to solve chemistry-related problems. Previous studies on students' conception have revealed that students have many alternatives conception in chemistry. The concepts examined include: Atomic Structure (Chiu, 2007); Chemical Equation and Formulae (Agung and Schwartz, 2007); Chemistry Periodic Table of Elements (Demircioglu et al., 2009); Chemical Bonding (Ozmen, 2004); Electrochemistry (Schmidt et al., 2007); Acids and Bases (Demircioglu et al., 2005) and Salts (Chandrasegaran et al., 2007).

Agung and Schwartz (2007) reported that educators and researchers have acknowledged that students' alternatives conception in science represents an important educational problem. To overcome this problem, Chung (2011) suggested that diagnostic assessment to be used as an effective tool for teachers to determine student readiness before instruction. Arguably, it is beneficial to identify students' alternatives conception so that teachers are able to formulate strategies which will enable students' to conceptualize more appropriately and enable them to improve their achievement in chemistry as a whole. This statement is in agreement with Ozmen (2004) that stated one of the most fruitful outcomes of the studies on children's misconceptions is to alert teachers to students' difficulties in conceptualizing science knowledge and hence suggest more effective strategies for improving their teaching and learning approaches.

Additionally, researchers also investigated students' socioeconomic background. Stewart (2008) reported that students who come from families with a high socioeconomic status are likely to achieve their academic goals. The Malaysian EPU (2009) reported that the poverty rate in Sabah in 2007 was 16\%; a much higher poverty rate than Sarawak $(4.2 \%)$ and Peninsular Malaysia $(2.3 \%)$. It is important to improve the academic results in chemistry so that students across Malaysia may choose to study the sciences at university level. Having higher academic qualifications will help the people of Sabah to attain social mobility and tackle poverty.

This study will report the study which has investigated the Malaysian students' achievement in the Conceptual Chemistry Test (CCT). Besides that, students' socio-economic status will also be profiled to see if they influence students' achievement in the CCT.

\subsection{Purpose of Study}

The purpose of this study is twofold: firstly, to profile students' conceptions in chemistry and secondly, to investigate whether students' achievements in the CCT differ significantly according to their socioeconomic background.

\section{MATERIALS AND METHODS}

This study employed a survey that involved some 317 Form Five students who are studying chemistry at schools and these were divided into two groups; High Socio-Economic (HSE) and Low Socio-Economic (LSE) based on their socio-economic background. The Local Municipal Council stated that a low income group family is one that earned less than USD250. These students are grouped as LSE whilst those families on a monthly income of USD500 and above are classed as HSE. 
Table 1. Area tested in conceptual chemistry test

\begin{tabular}{lll}
\hline Concept area & Item & Sources of question \\
\hline Atomic structure & 1,2 & Chiu (2007) \\
Chemical equation and formulae & 3,4 & Agung and Schwartz (2007) \\
Chemistry periodic table of elements & $5,6,7$ & Demircioglu et al. (2009) \\
Chemical bonding & $8,9,10$ & Ozmen (2004) \\
Electrochemistry & 11,12 & Schmidt et al. (2007) \\
Acids and bases & $13,14,15,16$ & Demircioglu et al. (2005) \\
Salts & 17 & Chiu (2007) \\
\hline
\end{tabular}

The study used a concept questionnaire of 23 multiple-choice items. This type of question provides only one correct answer; the other options (distracters) are incorrect. The concept questionnaire was replicated from previous research, as mentioned above. This study covers 7 topics from Form Four chemistry syllabuses. The topics covered are: (i) Atomic Structure; (ii) Chemical Equation and Formulae; (iii) Chemistry Periodic Table of Elements; (iv) Chemical Bonding; (v) Electrochemistry; (vi) Acids and Bases; and (vii) Salts.

\subsection{Research Instrument}

CCT was tested on 134 students. Students were instructed to complete all items in $40 \mathrm{~min}$. A brief questionnaire collecting personal details was also included in the test paper. All the questions given were translated from its initial language, English into Bahasa Malaysia. Thus, the pilot study was intended to ensure the clarity of the questions on the basis of language. The pilot study also ensured that the current chemistry curriculum covered the concepts in the questionnaire and that students had already learned the concepts. Table 1 shows some of the sources of the questions that were replicated in this study.

In order to examine the reliability of CCT, Linacre (2009) suggested the Rasch model of analysis using Winsteps ${ }^{\circledR}$ software version 3.69.0. Bond and Fox (2007) stated that the Rasch model of analysis assured one-dimensionality of certain constructs. The onedimensionality examination is important to ensure the reliability and validity of the instruments used. As mentioned, items were translated from English to Bahasa Malaysia. Thus, to increase face validity researchers also sought expert help in arranging and organising questionnaires.

From the analysis of pilot data, a calculation of the Kuder-Richardson (KR-20) for dichotomous data resulted in a value of 0.50 . Chandrasegaran et al.
(2007) in their report mentioned that Nunnally (1978) stated that the acceptable value of reliability for multiple choice items must be greater than 0.50 . Thus, some questions considered as useful were rewritten while others were eliminated.

\section{RESULTS}

The independent sample t-test was conducted to compare achievement in CCT between those in HSE and LSE income brackets. The analysis of t-test for students' achievement score in CCT revealed no significant differences. The difference in mean score of students' achievement in CCT is $[\mathrm{t}(256.04)=0.87$, $\mathrm{p}>0.05]$ (two-tailed). The mean score of students with HSE $(\mathrm{m}=34.84$, $\mathrm{sd}=14.20)$ is higher than the mean score for students with $\operatorname{LSE}(\mathrm{m}=33.57, \mathrm{sd}=11.18)$. The mean score of below 40 for both HSE and LSE students indicates that both groups have major alternatives conception in chemistry (Table 2).

For a detailed analysis on students' alternatives conception, a collection of most favoured distracters (alternatives conception that students held) was simplified and shown in Table 3. For each question, researchers provide one true answer (complete scientific answer) and three distracters (alternatives conception collected from previous research). Thus, in this study, each distracter that had been chosen with a value exceeding $25 \%$ is considered as students' alternatives conception.

The results as simplified in Table 3 shows that the majority of students hold an alternatives conception in the tested topics. Overall CCT contains 23 items and after analysis researchers found 17 concepts that student find hard to understand. Results also show the topic that students find most difficult is Acids and Bases. Further analysis of students' alternatives conception of item 2, 4, 6, 8, 11, 14 and 17 will be discussed in the following paragraphs. 
Table 2. T-test for comparing mean score of CCT

\begin{tabular}{lllllll}
\hline Group & $\mathrm{N}$ & Mean score & SD & t & df & Sig. \\
\hline HSE & 212 & 34.84 & 14.20 & 0.87 & 256.04 & 0.39 \\
LSE & 105 & 33.57 & 11.18 & & & \\
\hline
\end{tabular}

Table 3. List of students' alternatives conception in chemistry

\begin{tabular}{ll} 
Alternatives Conception & $\begin{array}{l}\text { Students with the Alternatives } \\
\text { Conception/\% }\end{array}$ \\
\hline Atomic Structure &
\end{tabular}

\section{Atomic Structure}

Heavier colored water particles moving down the glass, precipitated and forming $2 \quad 46$

different colored layer.

Colored water particles that poured into a glass of colorless water will change it into 26

colored water particles.

Friction of tyre and surface increases heat and thus increases the size of discrete particles. $\quad 30$

Chemical Equation and Formulae

Element with same relative atomic mass is an isotope.

Vaporized water inside closed tube will decrease in mass compared to liquid form.

Chemistry Periodic Table of Elements

Bromine is a good electric conductor compared to Nickel. $\quad 26$

Arrangement of elements in Periodic Table was based on number of Valens electron. $\quad 51$

Given that number of protons of element X is 9. Element Y positioned below element X in 27

same group in Periodic Table. Proton number of element $Y$ is 19.

Chemical Bonding

$\mathrm{Na}^{+}$ion with configuration of [2.8] is stable. $\quad 69$

$\mathrm{Mg}$ and $\mathrm{F}$ forming covalent bond.

$\begin{array}{ll}\text { Magnesium and Fluorine shared electron to achieve octet state. } & 30\end{array}$

Electrochemistry

$\mathrm{e}^{-}$moves from zinc half cell to copper half cell through porous disc. $\quad 31$

$\mathrm{e}^{-}$moves from copper half cell to zinc half cell through porous disc. $\quad 28$

Electrode that ion positive received electron is a negative pole for cell. 37

Electrode that releases electron to the outer circuit is a negative pole for cell. 28

Acids and Bases

$0.1 \mathrm{M} \mathrm{H}_{2} \mathrm{SO}_{3}$ is a strong acid. $\quad 39$

$\mathrm{H}_{2} \mathrm{SO}_{3}$ is a strong acid because it contains two Hydrogen atoms in its molecular compound. $\quad 32$

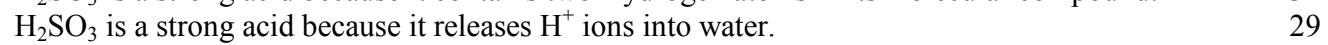

$\mathrm{H}_{2} \mathrm{SO}_{3}$ (with two hydrogen atoms) is stronger acid than $\mathrm{HNO}_{3}$ (one hydrogen atoms). $\quad 51$

$\mathrm{H}_{2} \mathrm{SO}_{3}$ is a strong acid because it completely dissociates in water. 40

Salts

When zinc powder is added into aqueous copper (II) sulfate, the colored solution becomes $\quad 29$

colorless because zinc is more reactive compared to copper (II) sulfate.

Table 4. Description of Item 2

Vehicle tyre pressure for everyday usage is $31 \mathrm{KPa}$. But for driving long distance in broad daylight, we should reduce air pressure inside tyre to $29 \mathrm{KPa}$. Explain why this action needs to be done.

A. Discrete particles move to the edge of the tyre and thus make it inflated.

B. Air pressure inside the tyre influences molecule shape and thus make the tyre inflated.

C. Friction of the tyre with road surface increases tyre temperature, eventually making discrete particles inflated and increasing in size and thus filling the space inside tyre.

D. The tyre becomes hot, kinetic energy of air discrete particle inside tyre increases and thus makes the tyre inflated and compact.

In item 2 (Table 4) students were posed a question about long distance driving in a broad daylight. Students were asked to give justification for the need to reduce air pressure inside tyres from normal pressure of $31 \mathrm{KPa}$ to
29 Kpa. Most of the students (47\%) gave a correct justification; the tyre becomes hot, the kinetic energy of air discrete particles inside the tyre increases and thus makes the tyre inflated and compact. Some of the 
students hold alternatives conception and give explanation that the friction of tyre and road surface increases heat and thus increases the size of air discrete particles.

Item 4 (Table 5) focuses on the conservation of mass in a closed system (the tube is sealed to avoid any particles escaping). In the problem a sealed tube with water (initially $25 \mathrm{~g}$ ) is heated until all the water is invisible. Students are then asked to determine the weight of the sealed tube. Half of the students had a tendency to answer that the initial weight of the sealed tube and its content will decrease. Only $25 \%$ of students understand the conservation of mass theory and know that the weight of the sealed tube remains same.

In item 6 students were asked about the arrangement of elements in the Periodic Table. A majority of $51 \%$ of the students had a tendency to choose the number of valence electron as a mean of arranging the elements in the Periodic Table. Only $41 \%$ of the students knew that the order of elements in the Periodic Table followed the number of protons in the nucleus (Table 6).

Item 11 deals with how electrons and ions flow through a porous disc in a galvanic cell. Students have to decide in which direction ions and electrons move through solution. From the analysis $31 \%$ of the students were attracted to statements " $\mathrm{e}$ - moves from zinc half cell to copper half cell through porous disc". The second most favored answer with $28 \%$ students choosing it was " $\mathrm{e}^{\text {- }}$ moves from copper half cell to zinc half cell through porous disc". From this result, it can be deduced that alternatives conception that students hold is that the electron travels through the solution from one electrode to the other. Only $27 \%$ were able to grasp the idea that $\mathrm{Zn}^{2+}$ ions flow from the zinc half cell to the copper half cell (Table 8).

As for item 8 (Table 7), students were asked to determine the noble gas arrangement necessary in order to achieve stability. Given that the $\mathrm{Na}^{+}$ion has a configuration of [2.8] the majority of $69 \%$ students determined that the configuration of [2.8] is stable. Only a small number of students (14\%) were able to identify that the $\mathrm{Na}^{+}$ion is not stable.

Item 14 asks students firstly if $\mathrm{H}_{2} \mathrm{SO}_{3}$ is a strong acid or not and secondly to give a reason for their answer Table 9. Results show that $32 \%$ of students stated that $\mathrm{H}_{2} \mathrm{SO}_{3}$ is a strong acid because it contains two hydrogen atoms in its molecular compound. The second most $(29 \%)$ favored alternatives conception is $\mathrm{H}_{2} \mathrm{SO}_{3}$ is a strong acid because it releases $\mathrm{H}^{+}$ions into water. Based on these results, it is clear that students focus more on the quantity of hydrogen atom or ions. Only $24 \%$ of the students give the correct answer; they reasoned that $\mathrm{H}_{2} \mathrm{SO}_{3}$ is not a strong acid because it does not dissociate completely in water.
Table 5. Description of Item 4

One gram of water is sealed in a strong tube. The tube and water together weigh 25 grams. The tube is heated until all the water boils and is no longer visible. How much will the sealed tube now weigh?
A. $25 \mathrm{~g}$
B. $26 \mathrm{~g}$
C. Less than $25 \mathrm{~g}$
D. Between $25 \mathrm{~g}$ and $26 \mathrm{~g}$

Table 6. Description of Item 6

The arrangement of elements in The Periodic Table of
Elements ais based on...
A. Atomic mass of elements
B. Number of electron valens
C. Number of protons in nucleus
D. Number of neutrons in nucleus

Table 7. Description of Item 8

Chemistry community stated that each atom should achieve noble gas arrangement to become stable. Is $\mathrm{Na}^{+}$ions with configuration [2.8] stable?
A. Stable
B. Not stable
C. Less stable
D. Neutral

Table 8. Description of Item 11

The diagram shows a galvanic cell and the reactions that occur at electrodes. Which of the following statements is true?

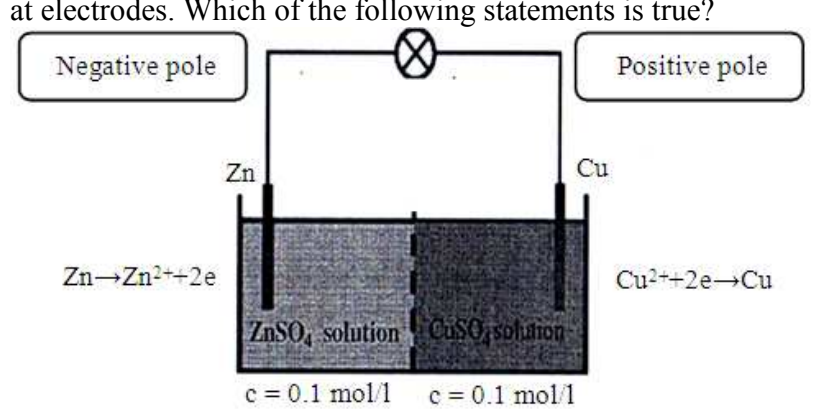

A. Electrons flow from the zinc half-cell to the copper half-cell through the porous disk.

B. Electrons flow from the copper half-cell to the zinc half-cell through the porous disk.

C. $\mathrm{Zn}^{2+}$ ions flow from the zinc half-cell to the copper half-cell through the porous disk.

D. $\mathrm{SO}_{4}{ }^{2-}$ ions flow from the zinc half-cell to the copper half-cell through the porous disk.

The result of item 17 as indicated in Table $\mathbf{1 0}$ shows that only $40 \%$ of the students gave the correct explanation that the solution becomes colorless because all the copper (II) sulfate had reacted completely. 
Table 9. Description of Item 14

In an experiment, students are given three acids as shown below.

To conduct an experiment, teacher then ask the students to used only strong acids.

\begin{tabular}{|c|c|c|}
\hline $0.1 \mathrm{Mol}$ & $0.1 \mathrm{Mol}$ \\
$\mathrm{HNO}_{3}$ & \begin{tabular}{|c|}
$0.1 \mathrm{Mol}$ \\
$\mathrm{H}_{2} \mathrm{SO}_{4}$
\end{tabular} \\
\hline
\end{tabular}

Please explain why $0.1 \mathrm{Mol} \mathrm{H}_{2} \mathrm{SO}_{3}$ is not a strong acid.

A. $\quad 0.1 \mathrm{Mol}$ of $\mathrm{H}_{2} \mathrm{SO}_{3}$ has the same concentration as other acid solutions but it is a weak acid. This acid does not completely disassociate in water.

B. $0.1 \mathrm{Mol}$ of $\mathrm{H}_{2} \mathrm{SO}_{4}$ and 0.1 of $\mathrm{Mol} \mathrm{H}_{2} \mathrm{SO}_{3}$ is a strong acid because both acid have two hydrogen atom in its molecule formula.

C. Sulphur and nitrogen component in acid makes it strong.

D. All acid dissociate $\mathrm{H}^{+}$ions in water.

Table 10. Description of Item 17

When powdered zinc is added to blue aqueous copper (II) sulfate and the mixture shaken, the blue colour of the solution gradually fades and it become colorless. At the same time a reddish-brown deposit is produced. The ionic equation is shown below:

$$
\mathrm{Zn}_{(\mathrm{s})}+\mathrm{Cu}_{(\mathrm{aq})}^{2+} \quad \mathrm{Zn}^{2+} \underset{(\mathrm{aq})+}{\longrightarrow} \mathrm{Cu}_{(\mathrm{s})}
$$

Why did the solution finally become colorless?

A. Cooper has formed a precipitate.

B. The copper (II) sulphate has completely reacted.

C. Zinc is more reactive than copper (II) sulphate.

D. Zinc has dissolved, just like sugar dissolves in water.

This item was replicated from Chandrasegaran et al. (2007) report and the present study results mirror their findings which revealed that a majority of $40 \%$ of students were able to answer correctly. In addition, the present study found that $29 \%$ of students hold an alternatives conception that zinc powder is more reactive than copper (II) sulfate. This shows that students do not know the series of metal reactivity, which clearly states the order of reactivity; zinc metal is more reactive than copper metal.

\section{DISCUSSION}

The results of the t-test clearly show that both HSE and LSE groups show no difference in CCT achievement mean score. This result was the opposite of Stewart (2008) who revealed that students with HSE have a higher academic achievement compared to students with LSE. It could be argued that the result of this study is due to the fact that both groups of students experienced the same learning process in the classroom and thus they acquired similar understanding of chemistry concepts being tested. In addition to that, they also shared the same learning materials.

Overall the results show that both HSE and LSE groups have a mean score below a minimum value of 40 . This indicates that both HSE and LSE groups hold major alternatives conception. This result reveals that Malaysian students as well as Taiwanese students (as reported in Chiu (2007)) have an incomplete, underdeveloped and flawed structure of various levels of knowledge and understanding about chemistry. To discuss further details about students' alternatives conception, researchers will explain one item from each topic. This is due to the fact that closer analysis of each topic as well as strategies students develop their alternatives conception should equip educators with richer information to plan strategies in remedying and rectifying students' misconceptions.

In item 2, students thought that the size of discrete particles increase when it is heated. This result is in accordance with Chiu (2007) who reports that students tended to think that the size of the gas particles inside the balloon increases when heated and thus particles move to the edge and make it larger. Based on this and previous studies, it could be argued that students have a tendency to think that the size of particles increases instead of its kinetic energy. This also shows that students could not relate the kinetic energy of air molecules to the inside of the tyre and pressure. This finding supports Morgil and Yoruk (2006) that reported students could not establish a connection between movement of molecules in the air and pressure. To remedy this alternative concept, teacher should focus on the kinetic energy of air particles, its movements and the effect of particles colliding inside the tyre (pressure).

Item 4 shows that students do not recognize that the mass of the sealed tube (closed system) should stay the same. This result shows that students ignored the conservation mass theory and the fact that matter, whether it be solid, liquid or gaseous, has mass. This argument is supported by previous research by Agung and Schwartz (2007) which found that students pointed out that gas was lighter. In the same report, Calik and Ayas (2005), explained that this alternatives concept is derived from the nature of gas which is invisible to the naked eye and thus must lack mass-a 'misconception'. 
Analysis of item 6 shows that more than half of the students assumed that valence electron was a method of arranging the elements in the Periodic Table. This result shows that students confused the concept of element arrangement with ways in grouping elements, which uses valens electron to indicate the elements group in the Periodic Table.

Result of item 8 show that students' alternatives conception focuses on octet state which is having eight electrons valence at the outer shell. This item is a replica from a previous study by Ozmen (2004). Both present and previous studies found that students tend to think $\mathrm{Na}^{+}$and other ions are stable because they have a filled outer shell. To explain this, Cokelez and Dumon (2005) referring to Robinson (2000), mentioned that students' use the rule of octet as a basic heuristic principle to explain the concept related to chemical bonding, chemical reaction and ion formation.

Coll (2008) also agreed with this statement and give evidence that the secondary school learners saw such bonding as driven by the octet rule. The evidence shows clearly that secondary students' thinking tends to generalize the octet rule and focused on the concept that 'one element requires electron from other elements to satisfy itself'. To avoid this alternatives conception, the teacher should therefore point out that any atom in an ion state is not stable. This will help the student not to generalize the basic concept of octet while explaining chemical bonding.

An analysis of item 11 shows that students assumed that ions move through the cell toward the plus pole. This result mirrors a previous study by Schmidt et al. (2007) that found students tend to think that charged particles (ions or electrons) flow through the internal circuit toward the plus pole. Students in this study tended to choose answer A and B which focuses on electron migration. This illustrates the fact that students assume that only electrons can migrate through a solution. The fact that charged particles, like ions that carry electrons, are able to migrate through a solution is being ignored.

In item 14 the results show that majority of students hold the alternatives conception that $\mathrm{H}_{2} \mathrm{SO}_{3}$ is a strong acid because it contains two hydrogen atoms in its molecular compound. This finding was consistent with Demircioglu et al. (2005) and Chiu (2007) which states that students considered that the more hydrogen atom a compound has, its acidity becomes stronger. This shows that students focus on the quantity of hydrogen atoms to determine the acidity of a compound. Demircioglu et al.
(2005) reports that students' explanation of an acid is based on sensory perception of the quantity of hydrogen atoms in the formula of an acid.

The result of item 17 shows that only $40 \%$ of the students gave the correct explanation that the solution becomes colorless because all the copper (II) sulfate had reacted completely. This item was replicated from Chandrasegaran et al. (2007) report and the present study results mirror their findings which revealed that a majority of $40 \%$ of students were able to answer correctly. In addition, the present study found that $29 \%$ of students hold an alternatives conception that zinc powder is more reactive than copper (II) sulfate. This shows that students do not know the series of metal reactivity, which clearly states the order of reactivity; zinc metal is more reactive than copper metal.

\section{CONCLUSION}

All the items in CCT were collected and replicated from previous studies conducted in different countries. It was found that Malaysian students had similar conceptions and misconceptions as those cited in the previous studies mentioned earlier. Thus, suggestions to improve students' conceptual understanding in the earlier studies could also be adapted in Malaysian classroom. Consequently, the CCT could be used prior to or after classroom instruction to identify students' alternatives conception. Based on the findings, teachers could plan and implement suggestions in this report and use it to reduce students' misunderstanding in chemistry.

Researchers suggest that teachers should provide students with opportunities to conduct experiments for themselves and discuss the finding among their peers. Justi and Gilbert (2000) in Cokelez and Dumon (2005) suggested that classroom discussion based on arguments or counter-arguments on chemistry concepts can facilitate students' conceptual understanding. This is reinforced by Demircioglu et al. (2005) who contend that chemistry concepts that relate to everyday life have a greater impact and are more readily understood in the learner's mind. Students who hold alternatives conception have a high resistance to modifying their preexisting ideas, even after classroom teaching and the completion of the learning process. Structured discussion gives the students an opportunity to understand the factors and sources of their alternatives conception.

In addition, Demircioglu et al. (2005) stated that teaching chemistry concepts and relating it to everyday life can help concept retention in a learner's mind for a 
much longer period. Thus, it is suggested that when preparing teaching and learning activities, teachers should integrate everyday substances and materials that could easily be found within the context of students' everyday life experiences. Another strategy is to conduct inquiry- based teaching in an effort to engage the students in the teaching and learning processes. If teachers discover that students are struggling to complete a task, they can use scaffolding techniques to coach and facilitate them. Taber (2003) explained that teachers should act as a learner's assistant to help student understanding of the subject. By doing this the teacher can help students to consolidate their conceptions. Another significant implication of this study is that teachers should carefully determine which students come from a low income family. This needs to be done so that any funds from the government and Ministry of Education can be distributed fairly to needy students.

To conclude, classroom instruction should be organized in a manner that remedies students' alternatives conception that has been identified in this study. When students' alternatives conception is challenged, they will realize that the conceptions that they hold are not scientifically acceptable. Correct conceptual understanding of chemistry and the ability to detect their own misconceptions will be the desired result of improved teaching methods. To improve the outcomes of chemistry learning, chemistry teachers should enrich the learning environment as well as encouraging students to actively participate in learning activities.

\section{REFERENCES}

Agung, S. and M.S. Schwartz, 2007. Students' understanding of conservation of matter, stoichiometry and balancing equations in Indonesia. Int. J. Sci. Educ., 29: 1679-1702. DOI: 10.1080/09500690601089927

Bond, T.G. and C.M. Fox, 2007. Applying the Rasch Model: Fundamental Measurement in the Human Sciences. 2nd Edn., Routledge, ISBN-10: 0805854614, pp: 340.

Calik, M. and A. Ayas, 2005. Exploring grade 7 - 10 students' comprehension related to the selected solution concepts on various mixtures. Turkish Educ. Sci., 3: 329-349.

Chandrasegaran, A.L., D.F. Treagust and M. Mocerino, 2007. The development of a two-tier multiple-choice diagnostic instrument for evaluating secondary school students' ability to describe and explain chemical reactions using multiple levels of representation. Chem. Educ. Res. Pract., 8: 293-307.
Chiu, M.H., 2007. A national survey of students' conceptions of chemistry in Taiwan. Int. J. Sci. Educ., 29: 421-452. DOI: 10.1080/09500690601072964

Chung, S.P., 2011. Using diagnostic assessment to help teachers understand the chemistry of the lead-acid battery. Chem. Educ. Res. Pract., 12: 228-237.

Cokelez, A. and A. Dumon, 2005. Atom and molecule: upper secondary school French students' representations in long-term memory. Chem. Educ. Res. Pract., 6: 119-135.

Coll, K.R., 2008. Chemistry learners' preferred mental models for chemical bonding. J. Turkish Sci. Educ., 5: 22-47.

Demircioglu, G., A. Ayas and H. Demircioglu, 2005. Conceptual change achieved through a new teaching program on acids and bases. Chem. Educ, Res. Pract., 6: 36-51.

Demircioglu, H., G. Demircioglu and M. Calik, 2009. Investigating the effectiveness of storylines embedded within a context-based approach: The case for the Periodic Table. Chem. Educ. Res. Pract., 10: 241-249. DOI: 10.1039/B914505M

Driver, R. and J. Easley, 1978. Pupils and paradigms: A review of literature related to concept development in adolescent science students. Stud. Sci. Educ., 5: 61-84. DOI: 10.1080/03057267808559857

EPU, 2009. Third essence: Addressing the socioeconomic inequality inequalities constructively and productively. Mid-term Review of the 9th Malaysia Plan (2006-2010). Department of Prime Minister.

Griffiths, A.K. and K.R. Preston, 1992. Grade-12 students' misconceptions relating to fundamental characteristics of atoms and molecules. J. Res. Sci. Teach., 29: 611-628. DOI: 10.1002/tea.3660290609

Justi, R. and J. Gilbert, 2000. History and philosophy of science through models: Some challenges in the case of 'the atom'. Int. J. Sci. Educ., 22: 993-1009. DOI: $10.1080 / 095006900416875$

Linacre, J.M., 2009. WINSTEPS and facets rasch software. Winsteps.

Morgil, I. and N. Yoruk, 2006. Cross-age study of the understanding of many concepts in chemistry subjects in science curriculum. J. Turkish Sci. Educ., 3: $16-27$.

Nunnally, J.C., 1978. Psychometric Theory. 2nd Edn., McGraw-Hill, ISBN-10: 0070474656, pp: 701. 
Ozmen, H., 2004. Some student misconceptions in chemistry: A literature review of chemical bonding. J. Sci. Educ. Technol., 13: 147-159. DOI: 10.1023/B:JOST.0000031255.92943.6d

Pfundt, H. and R. Duit, 1991. Students' Alternatives Framework and Science Education. 3rd Edn., Institute for Science Education at the University of Keil. Kiel, Germany.

Robinson, P.J., 2000. Temporal trends in United States dew point temperatures. Int. J. Climatol., 20: 985-1002. DOI: $\quad$ 10.1002/1097-0088(200007)20:9<985::AIDJOC513>3.0.CO;2-W

Ruddock, G.J., C.Y. O'Sullivan, A. Arora and E. Erberber, 2007. Developing the TIMSS 2007 mathematics and science assessments and scoring guides. TIMSS and PIRLS International Study Center, Lynch School of Education. Boston College.
Sanger, M.J. and T.J. Greenbowe, 1999. An analysis of college chemistry textbooks as sources of misconceptions and errors in electrochemistry. J. Chem. Educ., 76: 853-860. DOI: 10.1021/ed076p853

Schmidt, H.J., A. Marohn and A.G. Harisson, 2007. Factors that prevent learning in electrochemistry. J. Res. Sci. Teach., 44: 258-283. DOI: 10.1002/tea.20118

Stewart, E.B., 2008. School structural characteristics, student effort, peer associations and parental involvement. Educ. Urban City, 40: 179-204. DOI: 10.1177/0013124507304167

Taber, K.S., 2003. Responding to alternative conceptions in the classroom. School Sci. Rev., 84: 99-107.

TIMSS, 2007. TIMSS 2007 International Science Report: Findings from IEA's Trends in International Mathematics and Science Study at the Fourth and Eighth Grades. TIMSS \& PIRLS International Study Center. 